\title{
Association between clinicopathological factors and postoperative radiotherapy in patients with completely resected pathological N2 non-small cell lung cancer
}

\author{
YUJIN XU ${ }^{1,2}$, JIANQIANG LI ${ }^{3}$, JIN WANG ${ }^{1,2}$, XIAO HU ${ }^{1,2}$, \\ HONGLIAN MA ${ }^{1,2}, \mathrm{PU} \mathrm{LI}^{4}$, XIAO ZHENG ${ }^{1,2}$ and MING CHEN ${ }^{1,2}$
}

${ }^{1}$ Department of Radiation Oncology, Zhejiang Cancer Hospital; ${ }^{2}$ Zhejiang Provincial Key Laboratory of Radiation Oncology; Departments of ${ }^{3}$ Thoracic Surgery and ${ }^{4}$ Radiation Physics, Zhejiang Cancer Hospital, Hangzhou, Zhejiang 310022, P.R. China

Received December 16, 2016; Accepted October 13, 2017

DOI: $10.3892 / \mathrm{ol} .2017 .7601$

\begin{abstract}
The function of postoperative radiotherapy (PORT) in patients with completely resected pathologically N2 (pN2) non-small cell lung cancer (NSCLC) remains controversial due to a lack of prospective studies. The present study aimed to evaluate the efficacy of PORT in completely resected pN2 NSCLC when using modern radiation techniques, and to determine the associations between clinicopathological factors and PORT and survival rates. Following patient selection, 246 out of 269 consecutive patients with pN2 NSCLC were enrolled in the present study, with 88 patients having received postoperative chemotherapy (POCT) and PORT, 90 having received adjuvant chemotherapy, 1 having received adjuvant radiotherapy and the remaining 67 having received no adjuvant therapy. Overall survival (OS), local recurrence-free survival (LRFS) and disease-free survival (DFS) were estimated using the Kaplan-Meier method. The median age of the patients was 59 years, overall, $175(71.1 \%)$ of the patients were male and the median radiation dose was 50.4 Gy. The median follow-up duration was 38.3 months. The 1-, 3- and 5-year OS rates were 98.9, 71.3 and 54.9\%, and 93.0, 58.4 and $36.7 \%(\mathrm{P}=0.011)$ in the PORT and non-PORT group, respectively. The 1-, 3- and 5-year LRFS rates were 95.5, 84.6 and $78.0 \%$, and 86.6, 70.6 and $52.8 \%(\mathrm{P}<0.001)$ in the PORT and non-PORT groups, respectively. The 1-, 3- and 5-year DFS rates were $86.5,55.2$ and $37.9 \%$, and $80.9,40.3$ and $26.8 \%$ $(\mathrm{P}=0.132)$ in the PORT and non-PORT groups, respectively. Univariate analysis revealed that the OS rate was significantly increased in patients with peripheral tumors $(\mathrm{P}=0.029), \mathrm{pT} 1-2$ $(\mathrm{P}=0.015)$, one $\mathrm{N} 2$ lymph node $(\mathrm{LN})$ metastasis $(\mathrm{P}=0.001)$,
\end{abstract}

Correspondence to: Dr Ming Chen, Department of Radiation Oncology, Zhejiang Cancer Hospital, 1 Banshandong Road, Gongshu, Hangzhou, Zhejiang 310022, P.R. China

E-mail: chenming@zjcc.org.cn

Key words: non-small cell lung cancer, postoperative radiotherapy, clinicopathological factors, overall survival, prognostic factors single N2 station metastasis $(\mathrm{P}=0.030)$, no bronchial involvement $(\mathrm{P}=0.025)$, use of PORT $(\mathrm{P}=0.011)$ and POCT $(\mathrm{P}=0.003)$. Multivariate analysis revealed that PORT (HR, 0.755; 95\% CI, 0.498-0.986; P=0.047), POCT (HR, 0.645; 95\% CI, 0.420-0.988; $\mathrm{P}=0.044)$, bronchial involvement (HR, 1.453; 95\% CI, 1.002-2.107; P=0.049) and $\geq 2 \mathrm{~N} 2$ metastases (HR, $1.969 ; 95 \% \mathrm{CI}, 1.228-3.157 ; \mathrm{P}=0.005)$ were significant independent predictors of OS. Subgroup analysis demonstrated an increased OS rate with PORT only in the patients with positive bronchial involvement and $\geq 2 \mathrm{~N} 2 \mathrm{LN}$ metastases. The results revealed that PORT may improve the LRFS and OS rates in completely resected pN2 NSCLC, and that the patients with positive bronchial involvement and $\geq 2 \mathrm{~N} 2 \mathrm{LN}$ metastases may receive more benefit from PORT.

\section{Introduction}

Non-small cell lung cancer (NSCLC) remains the leading cause of cancer-associated mortality globally (1-3). Despite a number of diagnostic and therapeutic advancements having been achieved in the last thirty years the 5-year overall survival (OS) rate remains unsatisfactory at $\sim 16 \%(4,5)$. About one third of patients with NSCLC present with a locally advanced disease (at stages IIIA and B) (6). Particularly of note, completely resected NSCLC with pathologically confirmed $\mathrm{N} 2$ (pN2) stage NSCLC is a heterogeneous subgroup for different primary tumor status, clinical nodal stage and the extent of mediastinal lymph node (LN) involvement, with 5 -year OS rates in the range of 5 to $57 \%$ according to various prognostic factors (7-10). Postoperative chemotherapy (POCT) has been demonstrated by a number of studies to improve the OS rate of patients with pN2 NSCLC and has been regarded as the gold standard of treatment $(11,12)$. However, the risk of locoregional recurrence (LRR) remains as high as $20-40 \%$, which associates independently with worse OS (13). Postoperative radiotherapy (PORT) holds great appeal as a means by which to reduce LRR and improve OS. Up to now, the role of PORT remains controversial due to the lack of definitive evidence demonstrating a survival benefit (14-17). A PORT meta-analysis trialists group performed a meta-analysis in the 1990s, which indicated that 
PORT was not associated with any survival benefit in patients with resected pN2 NSCLC; the result may be as a result of lagging radiation techniques and high morbidity (18). Since the turn of the 21 st century, with improvements to modern radiation techniques, three-dimensional conformal radiotherapy (3D-CRT) and intensity-modulated radiation therapy (IMRT) have been widely applied (19). Under these new conditions, the role of PORT in patients with resected pN2 NSCLC should be re-evaluated. A subset analysis of the Adjuvant Navelbine International Trialist Association trial suggested a benefit in the OS of patients with pN2 treated with PORT, regardless of the use of POCT (20). In addition, analysis using the Surveillance, Epidemiology, and End Results database similarly indicated that PORT was associated with improved survival for patients with N2 stage disease (21). However, no definitive conclusion of the effectiveness of PORT in pN2 NSCLC may be drawn as no prospective randomized study using modern radiation techniques in the setting of adjuvant chemotherapy has been published thus far.

In the present study, the role of PORT in pN2 NSCLC and the association between clinicopathological factors and PORT were analyzed in patients with completely resected pN2 NSCLC.

\section{Patients and methods}

Patient selection. A total of 269 consecutive patients with pN2 NSCLC who underwent surgery at the Department of Thoracic Surgery at Zhejiang Cancer Hospital (Hangzhou, China) between January 2009 and December 2012 were included in the present retrospective study. The eligibility criteria of the present study included the following: i) Pathologically confirmed T1-3N2M0 stage IIIA according to the American Joint Committee on Cancer (AJCC) 7th lung cancer TNM classification (22); ii) radical resection was performed, namely, all patients underwent either sleeve resection, lobectomy or pneumonectomy; iii) the surgical margin was negative; iv) all patients received mediastinal lymphadenectomy or systematic mediastinal LN sampling; v) the patients demonstrated an Eastern Cooperative Oncology Group (ECOG) performance status (PS) of 0 or 1 (23); vi) patients underwent no neoadjuvant chemotherapy or chemoradiotherapy; and vii) complete information on tumor characteristics, pathological studies and follow-up data were available for all patients. In addition, patients who received sublobar resection or succumbed to postoperative complication within 3 months were excluded. As a result of the aforementioned selection criteria, the present study finally enrolled a total of 246 patients (175 male and 71 female; median age, 59 years, range, 38-71 years), including 213 who underwent lobectomy, 17 who underwent pneumonectomy and 16 who underwent sleeve resection. Among the 246 patients, 88 patients received POCT followed by PORT, 90 received adjuvant chemotherapy, 1 patient received adjuvant radiotherapy and the remaining 67 patients did not receive any adjuvant therapy. The Zhejiang Cancer Hospital Institutional Review Board approved the protocols for data collection and analysis in the present study. Clinical and pathological data was gathered primarily on the following patient characteristics: Sex, age, smoking history, ECOG PS, primary tumor location, extent of surgery, histology, pT stage, number of positive $\mathrm{N} 2$ nodes, number of $\mathrm{N} 2$ nodal stations involved, status of hilar LN, bronchial invasion, pulmonary vascular wall invasion, visceral pleura invasion, lymphovascular invasion and perineural invasion. Detailed patient characteristics are presented in Table I.

POCT. Of the 246 enrolled patients, 178 (72.4\%) were administered platinum-based adjuvant chemotherapy with a median of 4 cycles (range, 2-6): 63 patients received gemcitabine $\left(1,000 \mathrm{mg} / \mathrm{m}^{2}\right.$ intravenously, on days 1 and 8$)$ and cisplatin (25 mg/m² intravenously, on days 1-3); 52 patients received vinorelbine $\left(25 \mathrm{mg} / \mathrm{m}^{2}\right.$ intravenously, on days 1 and 8) and cisplatin $\left(25 \mathrm{mg} / \mathrm{m}^{2}\right.$ intravenously, on days $\left.1-3\right) ; 33$ patients received taxane-based $\left(135 \mathrm{mg} / \mathrm{m}^{2}\right.$ intravenously, on day 1) chemotherapy combined with cisplatin $\left(25 \mathrm{mg} / \mathrm{m}^{2}\right.$ intravenously, on days 1-3); 16 patients received pemetrexed $\left(500 \mathrm{mg} / \mathrm{m}^{2}\right.$ intravenously, on day 1) and cisplatin $\left(25 \mathrm{mg} / \mathrm{m}^{2}\right.$ intravenously, on days 1-3) and the remaining 14 patients received carboplatin-based (area under the curve $=5$ intravenously, on day 1 ) doublet chemotherapy. The reasons for patients not receiving adjuvant chemotherapy were mainly due to weakness, patient refusal or physician decision.

PORT. The administration of PORT was mainly based on the decision of the thoracic radiation oncologists. The clinical target volume (CTV) for left-sided lung cancer includes the bronchial stump (BS) and LN stations 2R, 2L, 4R, 4L, 5, 6, 7 and $10 \mathrm{~L}$ to $11 \mathrm{~L}$, while for right-sided lung cancer, the CTV includes the $\mathrm{BS}$ and $\mathrm{LN}$ stations $2 \mathrm{R}, 4 \mathrm{R}, 7$ and $10 \mathrm{R}$ to $11 \mathrm{R}$, according to the 7 th edition of International Association for the Study of Lung Cancer LN map (22).

The planning target volume (PTV) was defined as expanding the CTV by $0.6-0.8 \mathrm{~cm}$. The prescription dose was defined as $95 \%$ of the receiving dose of PTV, with the difference in internal target dose uniformity of $<5 \%$, and internal target maximum dose point $\leq 110 \%$. The percentage of the total normal lung volume receiving $\leq 20 \mathrm{~Gy}$ (V20) was $<25 \%$, the mean lung dose was $<13 \mathrm{~Gy}$, the spinal cord maximum dose was $<45 \mathrm{~Gy}$, the heart V40 was $<50 \%$ and the mean heart dose was $\leq 30$ Gy.

Follow-up. All patients underwent regular follow-ups in the Outpatient Department every 3 months over the first 2 years and every 6 months after that. Each visit included a medical history, physical examination, complete blood count, chest and upper abdominal computed tomography (CT), brain magnetic resonance imaging/CT and a bone scan (if deemed to be necessary due to complaint of pain). Local recurrence was defined as disease relapse at the BS, ipsilateral hilum and mediastinum; all other sites of failure, including the supraclavicular fossa and contralateral hilum, were considered to be distant metastases $(24,25)$. Disease progression was diagnosed with confirmed biopsy or positive imaging findings. If disease progression was suspected, positron emission tomography-CT was required.

Statistical analysis. A $\chi^{2}$ test was used to determine the distribution of patient characteristics within the PORT group and the non-PORT group. OS time was calculated from the first day of treatment to mortality from any cause or last follow-up and disease-free survival (DFS) time was calculated from the 
first day of treatment to disease progression, mortality or last follow-up. Local recurrence-free survival (LRFS) time was calculated from the first day of treatment to local recurrence, mortality or last follow-up. OS, DFS and LRFS rates were calculated using the Kaplan-Meier method. To determine prognostic value, study variables were compared with the survival measures using log-rank tests. The prognostic factors were determined using Cox's regression model. $\mathrm{P}<0.05$ was considered to indicate a statistically significant difference. All the analyses were performed using SPSS 21.0 (IBM Corp., Armonk, NY, USA).

\section{Results}

Patient and tumor characteristics. The detailed patient clinical and pathological characteristics are presented in Tables I and II, respectively. Median age was 59 years and the majority of patients were male (175 patients, $71.1 \%$ ). The factors were comparable between the PORT group and non-PORT group, with the exception that there were more patients treated with lobectomy and POCT in the PORT group. Of the 246 patients, $89(36.2 \%)$ received adjuvant PORT. Radiation was delivered with $6 \mathrm{MV}$ X-rays at 1.8-2 Gy/fraction once daily, 5 days/week, with a total dose ranging between 48.0 and $60.0 \mathrm{~Gy}$, and a median dose of 50.4 Gy. All patients who underwent PORT received 3D-CRT (40 patients) or IMRT (49 patients). The median time interval between surgery and the start of radiotherapy for all patients was 15.2 weeks (range, 3.4-24.8 weeks).

Survival analysis. The median follow-up time from the end of treatment was 38.3 months (range, 3.8-83.1 months). A total of 160 patients $(65.0 \%)$ experienced disease progression, of which 133 patients succumbed, during follow-up. The 1-, 3and 5-year OS rates in the PORT group were 98.9, 71.3 and $54.9 \%$, respectively, whereas the non-PORT group exhibited 1-, 3- and 5-year OS rates of 93.0, 58.4 and 36.7\%, respectively. A statistically significantly difference was indicated between the two groups $(\mathrm{P}=0.011$; Fig. 1A). A total of 65 (26.4\%) patients were diagnosed with local recurrence, and 16 with simultaneous local and distant progression during follow-up, with 1-, 3- and 5-year LRFS rates of 95.5, 84.6 and $78.0 \%$, respectively, in the PORT group, and 86.6, 70.6 and $52.8 \%$, respectively, in the non-PORT group $(\mathrm{P}<0.001$; Fig. 1B). Additionally, 79 (32.1\%) patients were diagnosed with distant metastasis during follow-up, combined with 16 patients demonstrating simultaneous local and distant progression. The 1-, 3- and 5-year DFS rates were 86.5, $55.237 .9 \%$, respectively, in the PORT group, and 80.9, 40.3 and $26.8 \%$, respectively, in the non-PORT group $(\mathrm{P}=0.132$; Fig. 1C). Distant metastasis occurred in the lungs $(n=36)$, supraclavicular fossa or contralateral hilum $(n=22)$, bone $(n=13)$, brain $(n=17)$, adrenal glands $(n=8)$, liver $(n=6)$ and other locations $(n=3)$.

Distinct treatment strategies were also investigated. The median OS times were as follows: For patients who underwent surgery followed by POCT and PORT, 76.03 months [95\% confidence interval (CI), 43.99-108.74]; for patients who underwent surgery followed by POCT, 49.83 months (95\% CI, 34.20-65.47); and finally for patients who underwent surgery alone, 38.87 months (95\% CI, 32.65-45.09) ( $\mathrm{P}=0.005$; Fig. 2).
Table I. Patient clinical characteristics.

\begin{tabular}{|c|c|c|c|c|}
\hline Variable & $\begin{array}{l}\text { Total, } \\
\mathrm{n}(\%)\end{array}$ & $\begin{array}{c}\text { PORT, } \\
\text { n }(\%)\end{array}$ & $\begin{array}{c}\text { Non-PORT, } \\
\text { n }(\%)\end{array}$ & P-value \\
\hline Sex & & & & 0.498 \\
\hline Male & $175(71.1)$ & $61(68.5)$ & $114(72.6)$ & \\
\hline Female & $71(28.9)$ & $28(31.5)$ & $43(27.4)$ & \\
\hline Age, years & & & & 0.376 \\
\hline$\leq 60$ & $129(52.4)$ & $50(56.2)$ & $79(50.3)$ & \\
\hline$>60$ & $117(47.6)$ & $39(43.8)$ & $78(49.7)$ & \\
\hline Smoking & & & & 0.289 \\
\hline Yes & $149(60.6)$ & $50(56.2)$ & $99(63.1)$ & \\
\hline No & $97(39.4)$ & $39(43.8)$ & $58(36.9)$ & \\
\hline ECOG PS & & & & 0.294 \\
\hline 0 & $184(74.8)$ & 70 (78.7) & $114(72.6)$ & \\
\hline 1 & $62(25.2)$ & $19(21.3)$ & $43(27.4)$ & \\
\hline Tumor location & & & & 0.692 \\
\hline LUL & 49 (19.9) & $22(24.7)$ & $27(17.2)$ & \\
\hline LLL & $42(17.1)$ & 15 (16.9) & $27(17.2)$ & \\
\hline RUL & $66(26.8)$ & $23(25.8)$ & $43(27.4)$ & \\
\hline RML & $14(5.7)$ & $5(5.6)$ & $9(5.7)$ & \\
\hline RLL & $75(30.5)$ & $24(27.0)$ & $51(32.5)$ & \\
\hline Tumor type & & & & 0.266 \\
\hline Central & $97(39.4)$ & $31(34.8)$ & $66(42.0)$ & \\
\hline Peripheral & $149(60.6)$ & $58(65.2)$ & $91(58.0)$ & \\
\hline Surgery & & & & 0.232 \\
\hline VATS & $38(15.4)$ & $17(19.1)$ & $21(13.4)$ & \\
\hline Thoracotomy & $208(84.6)$ & $72(80.9)$ & $136(86.6)$ & \\
\hline Extent of resection & & & & $0.007^{\mathrm{a}}$ \\
\hline Lobectomy & $229(93.1)$ & 88 (98.9) & $141(89.8)$ & \\
\hline Pneumonectomy & $17(6.9)$ & $1(1.1)$ & $16(10.2)$ & \\
\hline POCT & & & & $<0.001^{\mathrm{a}}$ \\
\hline Yes & $178(72.4)$ & 88 (98.9) & $90(57.3)$ & \\
\hline No & $68(27.6)$ & $1(1.1)$ & $67(42.7)$ & \\
\hline POCT cycles & & & & 0.082 \\
\hline$<3$ & $17(9.6)$ & $5(5.7)$ & $12(13.3)$ & \\
\hline$\geq 3$ & $161(90.4)$ & $83(94.3)$ & $78(86.7)$ & \\
\hline
\end{tabular}

${ }^{\mathrm{a}} \mathrm{P}<0.05$. PORT, postoperative radiotherapy; ECOG, Eastern Cooperative Oncology Group; PS, performance status; LLL, left lower lobe; LUL, left upper lobe; RLL, right lower lobe; RML, right middle lobe; RUL, right upper lobe; VATS, video-assisted thoracoscopic surgery; POCT, postoperative chemotherapy.

Univariate analysis. Univariate analysis was performed to determine the association between clinical and pathological factors, PORT and POCT treatments, and 5-year OS, DFS and LRFS rates. Results are presented in Table III. OS rates were identified to be significantly increased in patients with peripheral tumor $(\mathrm{P}=0.029)$, pT1-2 $(\mathrm{P}=0.015), 1 \mathrm{~N} 2 \mathrm{LN}$ metastasis $(\mathrm{P}=0.001)$, single $\mathrm{N} 2$ station metastasis $(\mathrm{P}=0.030)$, no bronchial involvement $(\mathrm{P}=0.025)$, and use of PORT $(\mathrm{P}=0.011)$ and POCT $(\mathrm{P}=0.003)$. Furthermore, pT1-2 $(\mathrm{P}=0.007), 1 \mathrm{~N} 2 \mathrm{LN}$ metastasis $(\mathrm{P}<0.001)$, single $\mathrm{N} 2$ station metastasis $(\mathrm{P}<0.001)$, 
Table II. Patient pathological characteristics.

\begin{tabular}{|c|c|c|c|c|}
\hline Variable & Total, n, (\%) & PORT, n (\%) & Non-PORT, n (\%) & $\mathrm{P}$-value \\
\hline \multicolumn{5}{|l|}{ Histology } \\
\hline $\mathrm{AC}$ & $136(55.3)$ & $56(62.9)$ & $80(51.0)$ & \\
\hline Non-AC & $110(44.7)$ & $33(37.1)$ & $77(49.0)$ & 0.070 \\
\hline \multicolumn{5}{|l|}{ pT stage } \\
\hline $\mathrm{T} 1-2$ & $210(85.4)$ & $78(87.6)$ & $132(84.1)$ & \\
\hline $\mathrm{T} 3$ & $36(14.6)$ & $11(12.4)$ & $25(15.9)$ & 0.447 \\
\hline \multicolumn{5}{|c|}{ Number of N2 metastasis } \\
\hline 1 & $102(41.5)$ & $37(41.6)$ & $65(41.4)$ & \\
\hline$\geq 2$ & $144(58.5)$ & $52(58.4)$ & $92(58.6)$ & 0.979 \\
\hline \multicolumn{5}{|c|}{ N2 station involved } \\
\hline Single & $160(65.0)$ & $56(62.9)$ & $104(66.2)$ & \\
\hline Multiple & $86(35.0)$ & $33(37.1)$ & $53(33.8)$ & 0.600 \\
\hline \multicolumn{5}{|c|}{ Hilar LN metastasis } \\
\hline Yes & $112(45.5)$ & $37(41.6)$ & $75(47.8)$ & \\
\hline No & $134(54.5)$ & $52(58.4)$ & $82(52.2)$ & 0.348 \\
\hline \multicolumn{5}{|c|}{ Bronchial involvement } \\
\hline Yes & $134(54.5)$ & $43(48.3)$ & $91(58.0)$ & \\
\hline No & $112(45.5)$ & $46(51.7)$ & $66(42.0)$ & 0.144 \\
\hline \multicolumn{5}{|c|}{ Pulmonary vascular wall invasion } \\
\hline Yes & $55(22.4)$ & $17(19.1)$ & $38(24.2)$ & \\
\hline No & $191(77.6)$ & $72(80.9)$ & $119(75.8)$ & 0.356 \\
\hline \multicolumn{5}{|c|}{ Visceral pleura invasion } \\
\hline Yes & $157(63.8)$ & $55(61.8)$ & $102(65.0)$ & \\
\hline No & $89(36.2)$ & $34(38.2)$ & $55(35.0)$ & 0.619 \\
\hline \multicolumn{5}{|c|}{ Lymphovascular invasion } \\
\hline Yes & $100(40.7)$ & $35(39.3)$ & $65(41.4)$ & \\
\hline No & $146(59.3)$ & $54(60.7)$ & $92(58.6)$ & 0.750 \\
\hline \multicolumn{5}{|c|}{ Perineural invasion } \\
\hline Yes & $51(20.7)$ & $19(21.3)$ & $32(20.4)$ & \\
\hline No & $195(79.3)$ & $70(78.7)$ & $125(79.6)$ & 0.857 \\
\hline
\end{tabular}

AC, adenocarcinoma; PORT, postoperative radiotherapy; LN, lymph node.

negative hilar LN metastasis $(\mathrm{P}=0.007)$ and no bronchial involvement $(\mathrm{P}=0.044)$ were associated with improved DFS rates. In addition, LRFS rates were significantly increased in females $(\mathrm{P}=0.036)$, ECOG $\mathrm{PS}=0(\mathrm{P}=0.024)$, peripheral tumor $(\mathrm{P}=0.015)$, lobectomy $(\mathrm{P}=0.005), 1 \mathrm{~N} 2 \mathrm{LN}$ metastasis $(\mathrm{P}=0.045)$, single $\mathrm{N} 2$ station metastasis $(\mathrm{P}=0.035)$, no bronchial involvement $(\mathrm{P}=0.029)$, and use of PORT $(\mathrm{P}<0.001)$ and $\operatorname{POCT}(\mathrm{P}=0.002)$.

Multivariate analysis. Based on the results of the univariate analysis, a multivariate analysis using Cox's regression model was performed to identify independent prognostic factors regarding survival and disease control. As presented in Table IV, the use of PORT (HR, 0.755; 95\% CI, 0.498-0.986; $\mathrm{P}=0.047$ ), the use of POCT (HR, 0.645; 95\% CI, 0.420-0.988; $\mathrm{P}=0.044)$, bronchial involvement ( $\mathrm{HR}, 1.453 ; 95 \% \mathrm{CI}$, 1.002-2.107; $\mathrm{P}=0.049)$ and $\geq 2 \mathrm{~N} 2$ metastases (HR, 1.969; 95\%
CI, 1.228-3.157; $\mathrm{P}=0.005)$ were identified to be significantly independent predictors of OS. Bronchial involvement (HR, 1.419; 95\% CI, 1.013-1.987; $\mathrm{P}=0.042)$ and $\geq 2 \mathrm{~N} 2$ metastases (HR, 1.807; 95\% CI, 1.173-2.783; $\mathrm{P}=0.007$ ) were associated with significantly worse DFS, and only PORT (HR, 0.488; 95\% CI, 0.271-0.881; $\mathrm{P}=0.017$ ) was an independent predictor of LRFS. Subgroup survival analysis was then performed for all patients based on the status of bronchial involvement and number of $\mathrm{N} 2$ metastases. The use of PORT was associated with a significantly increased OS rate in patients who were positive for bronchial involvement $(\mathrm{P}=0.037)$ and $\geq 2 \mathrm{~N} 2$ LN metastases $(\mathrm{P}=0.044)$; however, no association between patients with negative bronchial involvement $(\mathrm{P}=0.207)$ or $1 \mathrm{~N} 2$ metastasis $(\mathrm{P}=0.103)$ was indicated. Kaplan-Meier curves of the association between PORT and OS according to the status of bronchial involvement and number of N2 metastasis are presented in Figs. 3 and 4, demonstrating an improved OS 

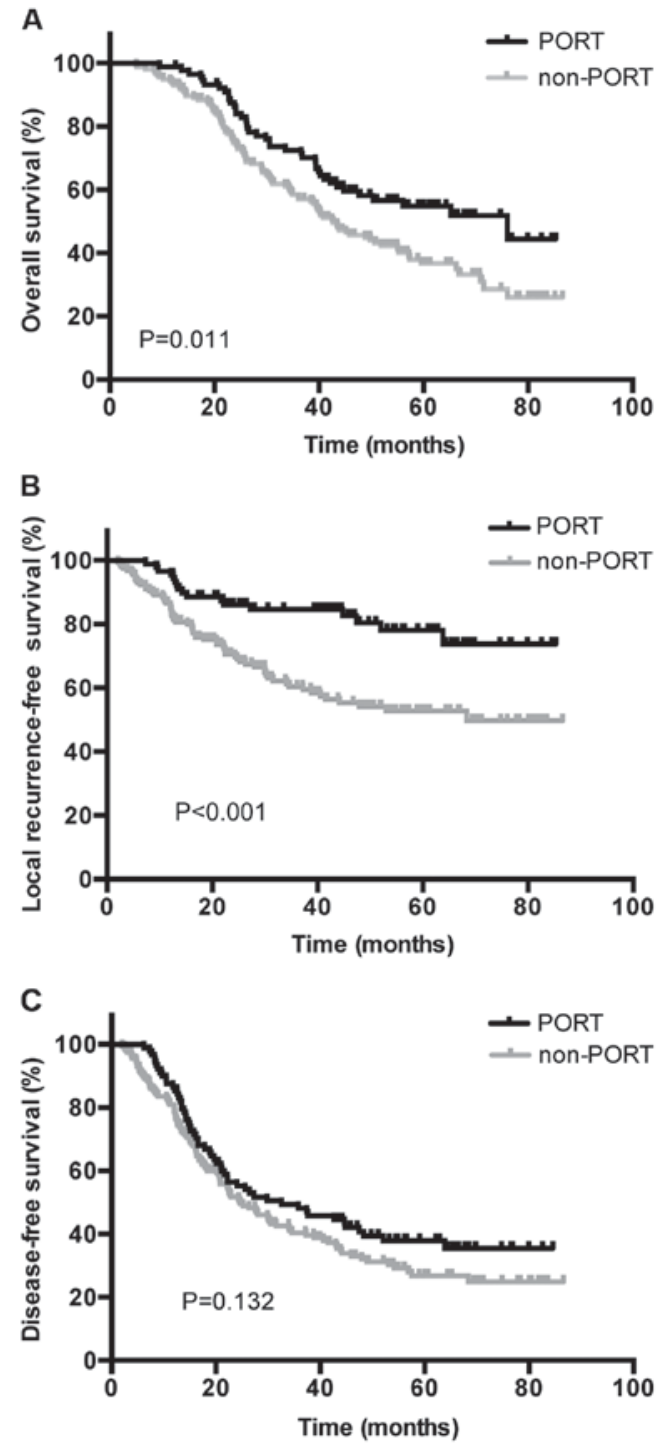

Figure 1. (A) OS, (B) LRFS and (C) DFS in PORT and non-PORT groups from total patient data. OS, overall survival; LRFS, local recurrence-free survival; DFS, disease-free survival; PORT, postoperative radiotherapy.

rate with PORT only in the subgroup of patients with positive bronchial involvement and $\geq 2 \mathrm{~N} 2 \mathrm{LN}$ metastases.

\section{Discussion}

The present study demonstrated that the use of PORT improved the OS rate $(\mathrm{P}=0.011)$ and LRFS rate $(\mathrm{P}<0.001)$ in patients with completely resected pN2 NSCLC compared with that in patients who were not treated with PORT. Results revealed that the optimal strategy for the treatment of postoperative pN2 NSCLC is adjuvant chemotherapy followed by radiotherapy. The median OS times of three treatment strategies, namely surgery followed by POCT and PORT, surgery followed by POCT or surgery alone, were 76.03 months (95\% CI, 43.99-108.74), 49.83 months (95\% CI, 34.20-65.47) and 38.87 months (95\% CI, 32.65-45.09), respectively $(\mathrm{P}=0.005)$. Patients with completely resected NSCLC and $\mathrm{pN} 2$ disease are extremely heterogeneous, and the treatment strategy is complex and variable, with survival rates ranging between 7 and $36 \%(9,26,27)$. With the wide use of modern

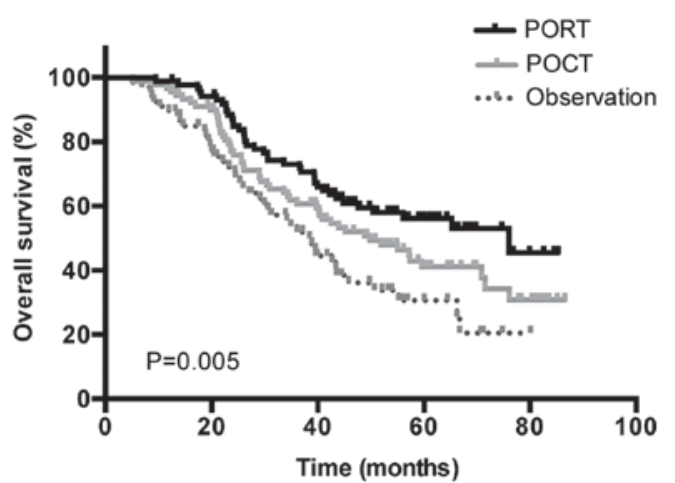

Figure 2. Overall survival for different treatment strategies from total patient data. Observation refers to the surgery-only group. PORT, postoperative radiotherapy; POCT, postoperative chemotherapy.

radiation techniques and adequate radiation dosages, a number of previous retrospective studies have demonstrated that PORT may improve the survival rates of patients with completely resected pN2 NSCLC (28-30).

Corso et al (31) retrospectively analyzed a total of 30,552 cases of stage II-IIIA R0 resection of NSCLC from the National Cancer Database of data gathered between 1998 and 2006. A total of 3,430 (11.2\%) patients received PORT, including 1,660 N2 patients. PORT was administered using 3D-CRT or IMRT. The results demonstrated that the 5-year survival rates in patients with $\mathrm{pN} 0$ and N1 with PORT were worse than those the patients with $\mathrm{pN} 0$ and $\mathrm{N} 1$ without PORT, at 48 vs. $37.7 \%(\mathrm{P}<0.001)$, and 39.4 vs. $34.8 \%(\mathrm{P}<0.001)$, respectively. Conversely, pN2 patients with PORT experienced a significantly improved 5-year survival rate compared with those without PORT $(\mathrm{P}<0.001)$.

Notably, to the best of our knowledge, all previous studies into the subject have been retrospective thus far, and prospective randomized studies are required to verify the conclusions. Lung ART, conducted by the Adjuvant Radiotherapy Lung Study Group, is an ongoing randomized controlled phase III study for comparing PORT with non-PORT in resected NSCLC with $\mathrm{N} 2$ using a modern radiotherapy technique. The research predicts to increase 3-year DFS rate by $10 \%$ (32).

Previous studies had reported that a number of pathological factors are associated with survival rate, including visceral pleural invasion (33), vascular invasion (34) and perineural invasion (35). In the present study, it was identified that bronchial involvement was an independent predictor of OS and DFS rates, however, the status of pulmonary vascular wall invasion, visceral pleural invasion, lymphovascular invasion and perineural invasion demonstrated no significant association with survival rate. In addition, the status of bronchial involvement was able to predict the efficacy of PORT. However, improved OS with PORT was only demonstrated in the subgroup of patients with positive bronchial involvement. To the best of our knowledge, no previous study has revealed the association between the status of bronchial involvement and the effect of PORT and prognosis. The risk of local relapse may be increased in the patients with positive bronchial involvement and PORT serves a crucial function in this subset. Additional research should be performed to verify the association between the pathological factors and 
Table III. Univariate analysis of prognostic factors for OS, DFS and LRFS.

\begin{tabular}{|c|c|c|c|c|c|c|}
\hline Variables & 5-year OS, \% & P-value & 5-year DFS, \% & P-value & 5-year LRFS, \% & P-value \\
\hline Sex & & 0.234 & & 0.337 & & $0.036^{\mathrm{a}}$ \\
\hline Male & 42.9 & & 30.1 & & 57.4 & \\
\hline Female & 44.5 & & 33.9 & & 74.8 & \\
\hline Age, years & & 0.917 & & 0.641 & & 0.078 \\
\hline$\leq 60$ & 43.0 & & 31.7 & & 71.1 & \\
\hline$>60$ & 43.4 & & 30.3 & & 51.8 & \\
\hline Smoking history & & 0.474 & & 0.534 & & 0.353 \\
\hline Yes & 43.2 & & 33.8 & & 59.8 & \\
\hline No & 43.6 & & 28.6 & & 68.7 & \\
\hline ECOG PS & & 0.290 & & 0.667 & & $0.024^{\mathrm{a}}$ \\
\hline 0 & 44.8 & & 32.6 & & 67.8 & \\
\hline 1 & 38.9 & & 28.4 & & 50.3 & \\
\hline Tumor location & & 0.461 & & 0.753 & & 0.543 \\
\hline LUL & 44.4 & & 33.7 & & 58.3 & \\
\hline LLL & 28.6 & & 31.9 & & 59.0 & \\
\hline RUL & 45.0 & & 22.3 & & 58.2 & \\
\hline RML & 32.3 & & 23.4 & & 72.9 & \\
\hline RLL & 49.6 & & 38.7 & & 67.0 & \\
\hline Tumor type & & $0.029^{\mathrm{a}}$ & & 0.542 & & $0.015^{\mathrm{a}}$ \\
\hline Central & 38.6 & & 32.7 & & 53.0 & \\
\hline Peripheral & 46.3 & & 30.0 & & 68.4 & \\
\hline Surgery method & & 0.357 & & 0.630 & & 0.559 \\
\hline VATS & 49.3 & & 24.9 & & 68.0 & \\
\hline Thoracotomy & 42.1 & & 32.2 & & 61.2 & \\
\hline Extent of resection & & 0.103 & & 0.135 & & $0.005^{\mathrm{a}}$ \\
\hline Lobectomy $^{\mathrm{b}}$ & 44.6 & & 32.1 & & 64.3 & \\
\hline Pneumonectomy & 18.4 & & 17.2 & & 37.1 & \\
\hline POCT & & $0.003^{\mathrm{a}}$ & & 0.387 & & $0.002^{\mathrm{a}}$ \\
\hline Yes & 47.9 & & 32.8 & & 68.6 & \\
\hline No & 30.0 & & 25.6 & & 44.0 & \\
\hline POCT cycles & & 0.280 & & 0.389 & & 0.551 \\
\hline $1-2$ & 47.1 & & 30.0 & & 64.7 & \\
\hline $3-4$ & 48.2 & & 34.1 & & 69.1 & \\
\hline Histology & & 0.354 & & 0.921 & & 0.105 \\
\hline $\mathrm{AC}$ & 43.5 & & 28.5 & & 67.1 & \\
\hline Non-AC & 42.8 & & 34.5 & & 56.9 & \\
\hline pT stage & & $0.015^{\mathrm{a}}$ & & $0.007^{\mathrm{a}}$ & & 0.161 \\
\hline $\mathrm{T} 1-2$ & 46.4 & & 34.2 & & 63.5 & \\
\hline $\mathrm{T} 3$ & 25.1 & & 11.8 & & 54.5 & \\
\hline Number of $\mathrm{N} 2$ metastasis & & $0.001^{\mathrm{a}}$ & & $<0.001^{\mathrm{a}}$ & & $0.045^{\mathrm{a}}$ \\
\hline 1 & 53.9 & & 45.1 & & 68.7 & \\
\hline$\geq 2$ & 35.7 & & 21.1 & & 57.5 & \\
\hline $\mathrm{N} 2$ station involved & & $0.030^{\mathrm{a}}$ & & $<0.001^{\mathrm{a}}$ & & $0.035^{\mathrm{a}}$ \\
\hline Single & 49.4 & & 38.9 & & 66.6 & \\
\hline Multiple & 31.1 & & 16.5 & & 53.9 & \\
\hline Hilar LN metastasis & & 0.055 & & $0.007^{\mathrm{a}}$ & & 0.251 \\
\hline Yes & 36.7 & & 23.3 & & 59.8 & \\
\hline No & 49.0 & & 37.9 & & 64.4 & \\
\hline Bronchial involvement & & $0.025^{\mathrm{a}}$ & & $0.044^{\mathrm{a}}$ & & $0.029^{\mathrm{a}}$ \\
\hline Yes & 37.9 & & 27.4 & & 58.2 & \\
\hline
\end{tabular}


Table III. Continued.

\begin{tabular}{|c|c|c|c|c|c|c|}
\hline Variables & 5-year OS, \% & P-value & 5-year DFS, \% & P-value & 5-year LRFS, \% & P-value \\
\hline No & 50.0 & & 35.3 & & 67.4 & \\
\hline Pulmonary vascular wall invasion & & 0.380 & & 0.314 & & 0.268 \\
\hline Yes & 31.9 & & 26.0 & & 58.6 & \\
\hline No & 46.6 & & 32.5 & & 63.8 & \\
\hline Visceral pleural invasion & & 0.213 & & 0.836 & & 0.195 \\
\hline Yes & 43.3 & & 29.9 & & 65.9 & \\
\hline No & 44.3 & & 33.1 & & 54.8 & \\
\hline Lymphovascular invasion & & 0.154 & & 0.364 & & 0.662 \\
\hline Yes & 35.0 & & 31.0 & & 64.7 & \\
\hline No & 48.5 & & 31.3 & & 61.4 & \\
\hline Perineural invasion & & 0.991 & & 0.971 & & 0.612 \\
\hline Yes & 46.8 & & 36.1 & & 61.4 & \\
\hline No & 42.5 & & 29.8 & & 62.3 & \\
\hline PORT & & $0.011^{\mathrm{a}}$ & & 0.132 & & $<0.001^{\mathrm{a}}$ \\
\hline Yes & 54.9 & & 37.9 & & 78.0 & \\
\hline No & 36.7 & & 26.8 & & 52.8 & \\
\hline
\end{tabular}

${ }^{\mathrm{a}} \mathrm{P}<0.05$. ${ }^{\mathrm{b}}$ Lobectomy included lobectomy, bi-lobectomy and lobectomy with bronchoplasty. OS, overall survival; DFS, disease-free survival; LRFS, local recurrence-free survival; ECOG, Eastern Cooperative Oncology Group; PS, performance status; LLL, left lower lobe; LUL, left upper lobe; RLL, right lower lobe; RML, right middle lobe; RUL, right upper lobe; VATS, video-assisted thoracoscopic surgery; AC, adenocarcinoma; POCT, postoperative chemotherapy; LN, lymph node; PORT, postoperative radiotherapy.

Table IV. Multivariate analyses of prognostic factors for OS, DFS and LRFS.

\begin{tabular}{|c|c|c|c|c|c|c|c|c|c|}
\hline \multirow[b]{2}{*}{ Variables } & \multicolumn{3}{|c|}{ Overall survival } & \multicolumn{3}{|c|}{ Disease-free survival } & \multicolumn{3}{|c|}{ Local recurrence-free survival } \\
\hline & HR & $95 \% \mathrm{CI}$ & P-value & HR & $95 \% \mathrm{CI}$ & P-value & HR & $95 \% \mathrm{CI}$ & P-value \\
\hline Female & 0.902 & $0.598-1.362$ & 0.624 & 0.828 & $0.571-1.202$ & 0.321 & 0.669 & $0.377-1.185$ & 0.168 \\
\hline $\mathrm{PS}=1$ & 1.046 & $0.702-1.558$ & 0.826 & 0.988 & $0.683-1.430$ & 0.950 & 1.449 & $0.894-2.346$ & 0.132 \\
\hline Peripheral tumor & 0.825 & $0.415-1.140$ & 0.053 & 0.925 & $0.644-1.329$ & 0.642 & 0.647 & $0.383-1.076$ & 0.093 \\
\hline Pneumonectomy & 0.598 & $0.288-1.244$ & 0.169 & 0.770 & $0.382-1.550$ & 0.464 & 1.200 & $0.508-2.836$ & 0.678 \\
\hline pT3 stage & 1.426 & $0.855-2.377$ & 0.174 & 1.330 & $0.961-1.841$ & 0.085 & 0.946 & $0.607-1.473$ & 0.805 \\
\hline Number of $\mathrm{N} 2$ metastasis $\geq 2$ & 1.969 & $1.228-3.157$ & $0.005^{\mathrm{a}}$ & 1.807 & $1.173-2.783$ & $0.007^{\mathrm{a}}$ & 1.235 & $0.663-2.301$ & 0.506 \\
\hline Multiple N2 stations involved & 0.978 & $0.618-1.550$ & 0.926 & 1.255 & $0.827-1.904$ & 0.286 & 1.618 & $0.881-2.969$ & 0.121 \\
\hline Hilar LN metastasis & 1.298 & $0.894-1.886$ & 0.171 & 1.319 & $0.937-1.858$ & 0.113 & 1.102 & $0.679-1.787$ & 0.694 \\
\hline Bronchial involvement & 1.453 & $1.002-2.107$ & $0.049^{\mathrm{a}}$ & 1.419 & $1.013-1.987$ & $0.042^{\mathrm{a}}$ & 1.496 & $0.916-2.444$ & 0.108 \\
\hline POCT & 0.645 & $0.420-0.988$ & $0.044^{\mathrm{a}}$ & 0.983 & $0.660-1.463$ & 0.908 & 0.735 & $0.437-1.236$ & 0.245 \\
\hline PORT & 0.755 & $0.498-0.986$ & $0.047^{\mathrm{a}}$ & 0.811 & $0.561-1.171$ & 0.263 & 0.488 & $0.271-0.881$ & $0.017^{\mathrm{a}}$ \\
\hline
\end{tabular}

${ }^{\mathrm{a} P}<0.05$. HR, hazard ratio; CI, confidence internal; OS, overall survival; DFS, disease-free survival; LRFS, local recurrence-free survival; PS, performance status; LN, lymph node; PORT, postoperative radiotherapy; POCT, postoperative chemotherapy.

the survival outcome and the efficacy of PORT in locally advanced NSCLC.

The number of LN metastases has been demonstrated to be a significant prognostic factor in a number of types of solid cancer and is also incorporated in the definition of $\mathrm{pN}$ stage in numerous types of cancer in the current TNM classification system, including breast, gastric and esophageal cancer (36). Notably, the prognostic value of the number of LN metastases in NSCLC has also been investigated in a number of studies, in which results have indicated that the number of LN metastases may be a superior prognostic indicator compared with the current location-based $\mathrm{pN}$ classification. In addition, the 

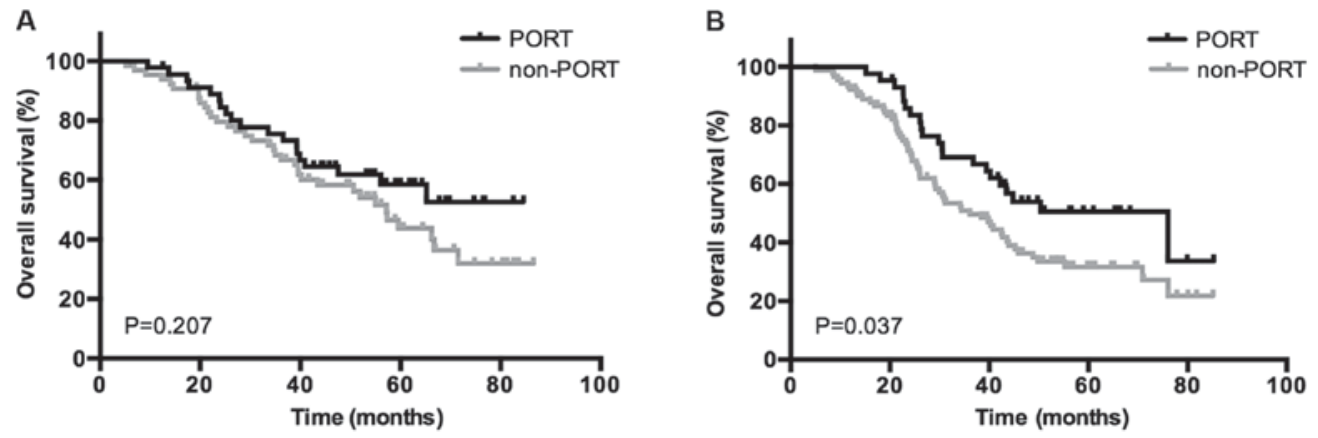

Figure 3. OS in the subgroup of patients who are (A) negative and (B) positive for bronchial involvement in the PORT and non-PORT groups. OS, overall survival; PORT, postoperative radiotherapy.
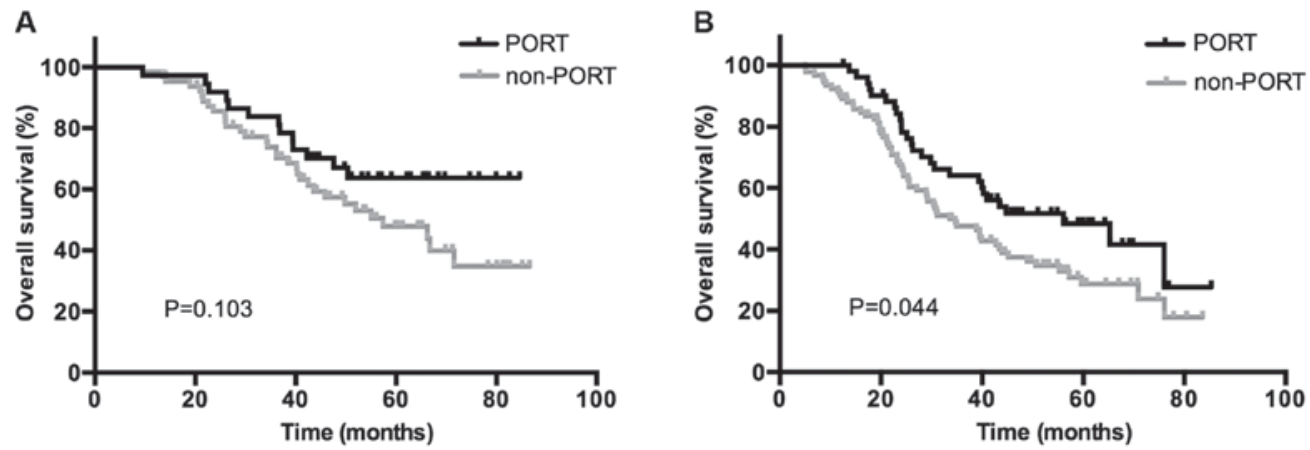

Figure 4. OS in the subgroup of patients with (A) 1 N2 lymph node metastasis and (B) $\geq 2$ N2 lymph node metastases in the PORT and non-PORT groups. OS, overall survival; PORT, postoperative radiotherapy.

significance of the number of metastatic LNs appeared to be more prominent in patients with pN2 compared with that in patients with $\mathrm{pN} 1(37,38)$. In the present study, univariate analysis demonstrated that patients who developed only 1 N2 LN metastasis experienced a significant improvement compared with multiple N2 metastases, not only in terms of OS rate, but also for DFS and LRFS rates. Multivariate analyses indicated that the number of metastatic LNs was a prognostic indicator of OS and DFS rates. Additionally, PORT treatment demonstrated an improved OS rate in the subgroup of patients with $\geq 2 \mathrm{~N} 2 \mathrm{LN}$ metastases compared with that in patients not treated with PORT, however, no significant difference was indicated in patients with $1 \mathrm{~N} 2 \mathrm{LN}$ metastasis. The results of the present study were in agreement with the aforementioned studies and indicated that PORT treatment improved survival rates in patients with multiple $\mathrm{N} 2 \mathrm{LN}$ metastases.

The univariate analysis performed in the present study demonstrated that multiple N2 station involvement was associated with a significantly poorer outcome not only in terms of OS rate, but also for DFS and LRFS rates $(\mathrm{P}=0.030, \mathrm{P}<0.001$, $\mathrm{P}=0.035$, respectively). However, multivariate analyses did not indicate its value as a prognostic factor in OS, DFS or LRFS. In addition, the number of $\mathrm{N} 2$ station involvements was unable to predict the efficacy of PORT, and there were no significant differences between the PORT and non-PORT groups in either single or multiple N2 station-involved subsets.

The present study demonstrates several limitations owing to the retrospective nature of the analysis. First, the patients all came from a single hospital and the number of cases was limited, which may confer selection bias. Secondly, adjuvant chemotherapy has been the standard treatment of IIIA NSCLC, however, only $72.4 \%$ of patients in the study accepted chemotherapy for various reasons, and almost all of PORT administrated was in a POCT setting, which may cause survival bias when analyzing the benefit of adjuvant radiotherapy. Thirdly, the majority of the enrolled patients were not tested for epidermal growth factor receptor (EGFR), anaplastic lymphoma kinase or B-RAF gene status. When the disease progressed, 28 patients were treated with EGFR inhibitors or other targeted therapies, which may exhibit distinct influences on the final OS rates. Finally, selected factors were based on the clinicopathological information available; treatment of NSCLC has already entered the molecular era and combining the clinicopathological factors and molecular biomarkers may be more relevant when analyzing the survival rates and effects of PORT.

In conclusion, the present study demonstrated that PORT may improve LRFS and OS rates in patients with resectable pN2 NSCLC. Adjuvant chemotherapy followed by radiotherapy was the optimal adjuvant treatment strategy. PORT, POCT, bronchial involvement status and number of N2 metastases were identified to be significant independent predictors of OS rate. Bronchial involvement and $\geq 2 \mathrm{~N} 2$ metastases were significantly associated with poorer DFS rates, and only PORT was an independent predictor of LRFS rate. PORT was associated with a significant increase in OS rates in patients with bronchial involvement and $\geq 2 \mathrm{~N} 2 \mathrm{LN}$ metastases. Further prospective studies to validate these results in a $\mathrm{pN} 2$ population are warranted. 


\section{Acknowledgements}

The present study was supported by the Key Project of Zhejiang Provincial Natural Science Foundation (grant no. LZ13H16003), and the Zhejiang Medical Science and Technology Foundation (grant no. 201480784).

\section{References}

1. Ettinger DS, Akerley W, Borghaei H, Chang AC, Cheney RT, Chirieac LR, D'Amico TA, Demmy TL, Ganti AK, Govindan R, et al: Non-small cell lung cancer. J Natl Compr Canc Netw 10: 1236-1271, 2012.

2. Ettinger DS, Akerley W, Borghaei H, Chang AC, Cheney RT, Chirieac LR, D'Amico TA, Demmy TL, Govindan R, Grannis FW Jr, et al: Non-small cell lung cancer, version 2.2013. J Natl Compr Canc Netw 11: 645-653, 2013.

3. Goeckenjan G, Sitter H, Thomas M, Branscheid D, Flentje M, Griesinger F, Niederle N, Stuschke M, Blum T, Deppermann KM, et al: Prevention, diagnosis, therapy, and follow-up of lung cancer: Interdisciplinary guideline of the German Respiratory Society and the German Cancer Society. Pneumologie 65: 39-59, 2011.

4. Alberg AJ, Brock MV, Ford JG, Samet JM and Spivack SD: Epidemiology of lung cancer: Diagnosis and management of lung cancer, 3rd ed: American College of Chest Physicians evidence-based clinical practice guidelines. Chest 143 (Suppl 5): e1S-e29S, 2013.

5. Hayat MJ, Howlader N, Reichman ME and Edwards BK: Cancer statistics, trends, and multiple primary cancer analyses from the surveillance, epidemiology, and end results (SEER) program. Oncologist 12: 20-37, 2007.

6. Mountain CF: Revisions in the international system for staging lung cancer. Chest 111: 1710-1717, 1997.

7. Lorent N, De Leyn P, Lievens Y, Verbeken E, Nackaerts K, Dooms C, Van Raemdonck D, Anrys B and Vansteenkiste J; Leuven Lung Cancer Group: Long-term survival of surgically staged IIIA-N2 non-small cell lung cancer treated with a surgical combined modality approach: Analysis of a 7-year prospective experience. Ann Oncol 15: 1645-1653, 2004.

8. Casali C, Stefani A, Natali P, Rossi G and Morandi U: Prognostic factors in surgically resected $\mathrm{N} 2$ non-small cell lung cancer: The importance of patterns of mediastinal lymph nodes metastases. Eur J Cardiothorac Surg 28: 33-38, 2005.

9. Andre F, Grunenwald D, Pignon JP, Dujon A, Pujol JL, Brichon PY, Brouchet L, Quoix E, Westeel V and Le Chevalier T: Survival of patients with resected N2 non-small cell lung cancer: Evidence for a subclassification and implications. J Clin Oncol 18: 2981-2989, 2000.

10. Suzuki K, Nagai K, Yoshida J, Nishimura M, Takahashi K and Nishiwaki Y: The prognosis of surgically resected N2 non-small cell lung cancer: The importance of clinical N status. J Thorac Cardiovasc Surg 118: 145-153, 1999.

11. Douillard JY, Rosell R, De Lena M, Carpagnano F, Ramlau R, Gonzáles-Larriba JL, Grodzki T, Pereira JR, Le Groumellec A, Lorusso V, et al: Adjuvant vinorelbine plus cisplatin versus observation in patients with completely resected stage IB-IIIA non-small-cell lung cancer (Adjuvant Navelbine International Trialist Association [ANITA]): A randomised controlled trial. Lancet Oncol 7: 719-727, 2006.

12. Arriagada R, Bergman B, Dunant A, Le Chevalier T, Pignon JP and Vansteenkiste J; International Adjuvant Lung Cancer Trial Collaborative Group: Cisplatin-based adjuvant chemotherapy in patients with completely resected non-small-cell lung cancer. N Engl J Med 350: 351-360, 2004.

13. Le Péchoux C: Role of postoperative radiotherapy in resected non-small cell lung cancer: A reassessment based on new data. Oncologist 16: 672-681, 2011.

14. No authors listed: Postoperative radiotherapy in non-small-cell lung cancer: Systematic review and meta-analysis of individual patient data from nine randomised controlled trials. PORT Meta-analysis Trialists Group. Lancet 352: 257-263, 1998.

15. Bekelman JE, Rosenzweig KE, Bach PB and Schrag D: Trends in the use of postoperative radiotherapy for resected non-small-cell lung cancer. Int J Radiat Oncol Biol Phys 66: 492-499, 2006.
16. Uno T, Sumi M, Kihara A, Numasaki H, Kawakami H, Ikeda H, Mitsumori M and Teshima T; Japanese PCS Working Subgroup of Lung Cancer: Postoperative radiotherapy for non-small-cell lung cancer: Results of the 1999-2001 patterns of care study nationwide process survey in Japan. Lung Cancer 56: 357-362, 2007.

17. Lally BE, Zelterman D, Colasanto JM, Haffty BG, Detterbeck FC and Wilson LD: Postoperative radiotherapy for stage II or III non-small-cell lung cancer using the surveillance, epidemiology, and end results database. J Clin Oncol 24: 2998-3006, 2006.

18. Le Péchoux C, Dunant A, Pignon JP, De Ruysscher D, Mornex F, Senan S, Casas F, Price A and Milleron B: Need for a new trial to evaluate adjuvant postoperative radiotherapy in non-small cell lung cancer patients with N2 mediastinal involvement. J Clin Oncol 25: e10-e11, 2007.

19. Zhang J, Yu XL, Zheng GF and Zhao F: Intensity-modulated radiotherapy and volumetric-modulated arc therapy have distinct clinical advantages in non-small cell lung cancer treatment. Med Oncol 32: 94, 2015.

20. Douillard JY, Rosell R, De Lena M, Riggi M, Hurteloup P and Mahe MA; Adjuvant Navelbine International Trialist Association: Impact of postoperative radiation therapy on survival in patients with complete resection and stage I, II, or IIIA non-small cell lung cancer treated with adjuvant chemotherapy: The adjuvant Navelbine international trialist association (ANITA) randomized trial. Int J Radiat Oncol Biol Phys 72: 695-701, 2008.

21. Lally BE, Zelterman D, Colasanto JM, Haffty BG, Detterbeck FC and Wilson LD: Postoperative radiotherapy for stage II or III non-small cell lung cancer using the surveillance, epidemiology, and end results database. J Clin Oncol 24: 2998-3006, 2006.

22. Rusch VW, Asamura H, Watanabe H, Giroux DJ, Rami-Porta R and Goldstraw P; Members of IASLC Staging Committee: The IASLC lung cancer staging project: A proposal for a new international lymph node map in the forthcoming seventh edition of the TNM classification for lung cancer. J Thorac Oncol 4: 568-577, 2009.

23. Oken MM, Creech RH, Tormey DC, Horton J, Davis TE, McFadden ET and Carbone PP: Toxicity and response criteria of the Eastern Cooperative Oncology Group. Am J Clin Oncol 5: 649-655, 1982 .

24. Higgins KA, Chino JP, Berry M, Ready N, Boyd J, Yoo DS and Kelsey CR: Local failure in resected N1 lung cancer: Implications for adjuvant therapy. Int J Radiat Oncol Biol Phys 83: 727-733, 2012.

25. Varlotto JM, Yao AN, DeCamp MM, Ramakrishna S, Recht A, Flickinger J, Andrei A, Reed MF, Toth JW, Fizgerald TJ, et al: Nodal stage of surgically resected non-small cell lung cancer and its effect on recurrence patterns and overall survival. Int J Radiat Oncol Biol Phys 91: 765-773, 2015.

26. Kim KJ, Ahn YC, Lim DH, Han J, Park K, Park JO, Kim K, Kim J and Shim YM: Analyses on prognostic factors following tri-modality therapy for stage IIIa non-small cell lung cancer. Lung Cancer 55: 329-336, 2007.

27. Casali C, Stefani A, Natali P, Rossi G and Morandi U: Prognostic factors in surgically resected N2 non-small cell lung cancer: The importance of patterns of mediastinal lymph nodes metastasis. Eur J Cardiothorac Surg 28: 33-38, 2005.

28. Zou B, Xu Y, Li T, Li W, Tang B, Zhou L, Li L, Liu Y, Zhu J, Huang M, et al: A multicenter retrospective analysis of survival outcome following postoperative chemoradiotherapy in non-small-cell lung cancer patients with $\mathrm{N} 2$ nodal disease. Int J Radiat Oncol Biol Phys 77: 321-328, 2010.

29. Patel SH, Ma Y, Wernicke AG, Nori D, Chao KS and Parashar B: Evidence supporting contemporary post-operative radiation therapy (PORT) using linear accelerators in N2 lung cancer. Lung Cancer 84: 156-160, 2014.

30. Billiet C, Decaluwé H, Peeters S, Vansteenkiste J, Dooms C, Haustermans K, De Leyn P and De Ruysscher D: Modern post-operative radiotherapy for stage III non-small cell lung cancer may improve local control and survival: A meta-analysis. Radiother Oncol 110: 3-8, 2014.

31. Corso CD, Rutter CE, Wilson LD, Kim AW, Decker RH and Husain ZA: Re-evaluation of the role of postoperative radiotherapy and the impact of radiation dose for non-small-cell lung cancer using the National Cancer Database. J Thora Oncol 10: 148-155, 2015.

32. Finn CF, Pechoux CL, Edwards J and Lunt C: 189: Lung ART: Phase III study comparing post-operative conformal radiotherapy to no post-operative radiotherapy in patients with completely resected non-small cell lung cancer and mediastinal N2 involvement. Lung Cancer 87 (Suppl 1): S70-S71, 2015. 
33. Ou SH, Zell JA, Ziagos A and Anton-Culver H: Prognostic significance of the non-size-based AJCC T2 descriptors: Visceral pleura invasion, hilar atelectasis, or obstructive pneumonia in stage IB non-small cell lung cancer is dependent on size. Chest 133: 662-669, 2008

34. Tsuchiya T, Hashizume S, Akamine S, Muraoka M, Honda S, Tsuji K, Urabe S, Hayashi T, Yamasaki N and Nagayasu T: Upstaging by vessel invasion improves the pathology staging system of non-small cell lung cancer. Chest 132: 170-177, 2007.

35. Yilmaz A, Duyar SS, Cakir E, Aydin E, Demirag F, Karakaya J, Yazici U and Erdogan Y: Clinical impact of visceral pleural, lymphovascular and perineural invasion in completely resected non-small cell lung cancer. Eur J Cardiothorac Surg 40: 664-670, 2011.
36. Edge SB and Compton CC: The American Joint Committee on Cancer: The 7th edition of the AJCC cancer staging manual and the future of TNM. Ann Surg Oncol 17: 1471-1474, 2010.

37. Wei S, Asamura H, Kawachi R, Sakurai H and Watanabe S: Which is the better prognostic factor for resected non-small cell lung cancer: The number of metastatic lymph nodes or the currently used nodal stage classification? J Thorac Oncol 6: 310-318, 2011.

38. Lee JG, Lee CY, Park IK, Kim DJ, Park SY, Kim KD and Chung KY: Number of metastatic lymph nodes in resected non-small cell lung cancer predicts patient survival. Ann Thorac Surg 85: 211-215, 2008. 